\title{
Response of the meridional overturning circulation to variable buoyancy forcing in a double hemisphere basin
}

\author{
Marc A. Lucas · J. J.-M. Hirschi · J. Marotzke
}

Received: 3 September 2008/Accepted: 2 November 2009/Published online: 18 November 2009

(C) The Author(s) 2009. This article is published with open access at Springerlink.com

\begin{abstract}
We consider how a highly idealized doublehemisphere basin responds to a zonally constant restoring surface temperature profile that oscillates in time, with periods ranging from 0.5 to 32,000 years. In both hemispheres, the forcing is similar but can be either in phase or out of phase. The set-up is such that the Northern Hemisphere always produces the densest waters. The model's meridional overturning circulation (MOC) exhibits a strong response in both hemispheres on decadal to multi-millennial timescales. The amplitude of the oscillations reaches up to $140 \%$ of the steady-state maximum MOC and exhibits resonance-like behaviour, with a maximum at centennial to millennial forcing periods. When the forcing is in phase between the Northern and Southern Hemispheres, there is a marked decrease in the amplitude of the MOC response as the forcing period is increased beyond the resonance period. In this case the resonance-like behaviour is identical to the one we found earlier in a single-hemisphere model and occurs for the same reasons. When the forcing is out of phase between the Northern and Southern Hemispheres, the amplitude of the MOC response is substantially greater for long forcing periods (millennial
\end{abstract}

M. A. Lucas · J. J.-M. Hirschi

School of Ocean and Earth Science,

National Oceanography Centre, University of Southampton,

Southampton, European Way, Southampton SO14 3ZH, UK

M. A. Lucas $(\square)$

Collecte Localisation Satellite,

8-10 Rue Hermes, Parc technologique du Canal,

31500 Ramonville Saint Agne, France

e-mail:marc.lucas@cls.fr; mlucas@cls.fr

J. Marotzke

Max-Planck-Institut für Meteorologie,

Bundesstr. 53, 20146 Hamburg, Germany and longer), particularly in the Southern Hemisphere. This increased MOC amplitude occurs because for an out of phase forcing, either the northern or the southern deep water source is always active, leading to generally colder bottom waters and thus greater stratification in the opposite hemisphere. This increased stratification in turn stabilises the water column and thus reduces the strength of the weaker overturning cell. The interaction of the two hemispheres leads to response timescales of the deep ocean at half the forcing period. Our results suggest a possible explanation for the half-precessional time scale observed in the deep Atlantic Ocean palaeo-temperature record.

\section{Introduction}

Naturally occurring cycles in the climate system is an area of ongoing studies. These cycles cover a broad band of frequencies ranging from daily to orbital (Milankovitch 1920) and geological times scales. Some of these cycles mainly reflect the internal variability of the Earth climate system (e.g. El Nino Southern Oscillation, Quasi Biennial Oscillation, Min et al. 2005), whereas others are externally driven (Solar, Orbital). Internal and external cycles can interact in a non linear fashion and involve several constituents of the climate system (Tziperman et al. 1994). Generally though, because the atmosphere responds the fastest and has been extensively sampled over the last 100 years, natural atmospheric cycles are better understood. In the ocean, naturally occurring cycles are less well known and yet the response of the ocean to cyclic external forcing is of great importance as the ocean is considered as a pacemaker of the climate system (Huybers and Curry 2006). In particular, the meridional heat transport by the Meridional Overturning Circulation (MOC) has significant 
climatic consequence (Manabe and Stouffer 1988; Rahmstorf and Ganopolski 1999), as it transfers energy from the low latitudes to the high latitudes (over $1 \mathrm{PW}$ in the North Atlantic, Ganachaud and Wunsch 2000). This paper is concerned with the dynamics of the ocean MOC under periodic (cyclical) surface buoyancy forcing, with the broader aim of investigating how the MOC could play an important role in orbital-timescale climate variations.

In today's ocean the MOC is characterized by deep water formation at high northern and southern latitudes. Therefore, these latitudes are obvious locations to investigate the impact of surface forcings on the MOC, which is by no means constant. Recent observations by Cunningham et al. (2007) and Kanzow et al. (2007) have shown a large variability of the Atlantic MOC at $26^{\circ} \mathrm{N}$. However, it is still unclear if this variability is representative of the entire North Atlantic or rather locally induced (e.g., Hirschi et al. 2007). Results from numerical studies suggest that the MOC undergoes changes on timescales of decades and longer (e.g., Delworth et al. 1993; Delworth and Greatbatch 2000). There are also suggestions that well-documented palaeo events such as Heinrich ice rafting events (Heinrich 1988) and Dansgaard/Oeschger events (Dansgaard et al. 1993) coincided with a slow down or even a shut down of the deep water production in the North Atlantic (McManus et al. 2004) although there is as yet no consensus (Wunsch 2006).

The fundamentals of how the deep water production and hence the MOC respond to variable large-scale buoyancy forcing has not received much attention yet. Lucas et al. (2005) showed that the response of the deep circulation to oscillations in surface buoyancy forcing is large (up to $120 \%$ of the maximum steady state value), depends strongly on the period of the forcing, and is remote from a quasi-steady state response even for forcing timescales of 32,000 years. Here, we extend these results by including a second hemisphere. Indeed, interhemispheric dynamics have been shown to be crucial for the dynamics and stability of the MOC (Klinger and Marotzke 1999, 2000; Marotzke and Klinger 2000) Hence to get a proper hold on the circulation in the North Atlantic, considering the other hemisphere is essential. A double-hemisphere study has the important added complexity of theoretically allowing the existence of two high latitude deep water production sites, a situation much closer to what is observed in today's ocean with deep water production in the North Atlantic and to a lesser extent in the Weddell Sea (Pickard and Emery 1990). These two deep water formation sites produce waters, the temperature of which is not identical due to the thermal asymmetry between the two hemispheres (Bjornsson and Toggweiler 2001). What will be the impact of the second source of deep water on the resonance-like behaviour identified by Lucas et al. (2005)? How will the amplitude of the response be affected by the thermal asymmetry (Biastoch et al. 2008)?

The aim of this paper is to study the response of the ocean to cyclic external thermal forcing in a series of idealised numerical experiments that take into account the inter-hemispheric geometry. Two basic setups are considered: one where the forcing in the two hemispheres is synchronous and the other where there is a lag of half a forcing period between the two. These two possibilities reflect, in the simplest possible way, that the basic Milankovitch forcing can be either symmetric about the equator (eccentricity forcing) or antisymmetric (tilt forcing and precession). This paper is structured as follows. Section 2 describes the model setup and the experiments. Section 3 presents the results for the asymptotic (time-independent) forcing. Section 4 contains the results of the experiments with an oscillatory forcing. Finally, Sect. 5 discusses and summarises our principal results.

\section{Model description}

\subsection{Model configuration}

The experimental set-up in this study is identical to that of Lucas et al. (2005) except that the ocean basin now spans both hemispheres The model is a parallelised version of the GFDL MOM model which can distribute the various processes on an array of processors (Webb 1996). The free surface numerics have been updated by including the free surface numerical code of OCCAM (Webb 1995). The model also includes the eddy parameterisation scheme of Gent and McWilliams (1990) as implemented by Griffies (1998).

The domain is a $60^{\circ}$ wide basin extending from $60^{\circ} \mathrm{S}$ to $60^{\circ} \mathrm{N}$ with no circumpolar current. The horizontal resolution is $4^{\circ} \times 4^{\circ}$, and there are 15 levels in the vertical. The ocean depth is $5,300 \mathrm{~m}$ everywhere, and the thickness of the depth levels varies from $30 \mathrm{~m}$ at the surface to $836 \mathrm{~m}$ at level 15 . The vertical diffusion is homogeneous throughout the basin, set at $10^{-4} \mathrm{~m}^{2} / \mathrm{s}$, the lateral eddy diffusivity is $2 \times 10^{7} \mathrm{~cm}^{2} / \mathrm{s}$, the lateral eddy viscosity set at $10^{9} \mathrm{~cm}^{2} / \mathrm{s}$ and the isopycnal tracer diffusivity has a value of $2 \times 10^{7} \mathrm{~cm}^{2} / \mathrm{s}$. In the initial conditions, the salinity is set to 35 psu throughout the model, and the (virtual) surface salinity fluxes are set to zero. The wind effect is removed by setting all the surface wind stresses to zero. The temperature fields are initialised by setting the surface temperature to $20^{\circ} \mathrm{C}$ everywhere and decreasing it by $1^{\circ} \mathrm{C}$ at each level. Thus, the coldest temperature is at the bottom and is $5^{\circ} \mathrm{C}$. The temperature is forced at the surface using a Newtonian relaxation scheme, where the restoring period is set to 40 days. 
Table 1 Summary of experiments with oscillating forcing $(\mathrm{O})$ and steady forcing (S)

See main text for details

\begin{tabular}{llllll}
\hline $\begin{array}{l}\text { Name of } \\
\text { experiment }\end{array}$ & $F_{\mathrm{N}}$ & $\begin{array}{l}\text { Northernmost } \\
\text { temperature range } \\
\text { in }{ }^{\circ} \mathrm{C}\end{array}$ & $F_{\mathrm{S}}$ & $\begin{array}{l}\text { Southernmost } \\
\text { temperature range } \\
\text { in }{ }^{\circ} \mathrm{C}\end{array}$ & $\begin{array}{l}\text { Lag in the forcing } \\
\text { between the two } \\
\text { hemispheres (radians) }\end{array}$ \\
\hline O4-4 & 13 & $0-4$ & 13 & $0-4$ & 0 \\
O4-5 & 13 & $0-4$ & 12.5 & $1-5$ & 0 \\
O4-4A & 13 & $0-4$ & 13 & $0-4$ & $\pi$ \\
O4-5A & 13 & $0-4$ & 12.5 & $1-5$ & $\pi$ \\
O4-7A & 13 & $0-4$ & 11.5 & $3-7$ & $\pi$ \\
S0-0 & NA & Fixed: 0 & NA & Fixed: 0 & NA \\
S0-1 & NA & Fixed: 0 & NA & Fixed: 1 & NA \\
S0-4 & NA & Fixed: 0 & NA & Fixed: 4 & NA \\
S0-5 & NA & Fixed: 0 & NA & Fixed: 5 & NA \\
S4-1 & NA & Fixed: 4 & NA & Fixed: 1 & NA \\
S4-4 & NA & Fixed: 4 & NA & Fixed: 4 & NA \\
S4-5 & NA & Fixed: 4 & NA & Fixed: 5 & NA
\end{tabular}

\subsection{Experimental strategy}

The purpose of this study is to investigate the response of the large scale oceanic circulation to variable buoyancy forcing. As we are primarily interested in deep water production, our experimental set-up aims to reproduce winter conditions. An overview of all numerical experiments and of the buoyancy forcing periods used is given in Tables 1 and 2, respectively. We use a sinusoidal restoring temperature profile, which varies with latitude and time according to:

$T(\varphi, t)=\left(F_{\mathrm{H}}+\cos (2 \pi t / P+S)\right) \times(\cos (3 \varphi)-1)+28$,

where $T$ is the restoring temperature, $\Phi$ is latitude, $t$ is time, $P$ the forcing period and $F_{\mathrm{H}}$ a parameter specific to each hemisphere $\left(F_{\mathrm{N}}\right.$, parameter for the Northern Hemisphere, $F_{\mathrm{S}}$, parameter for the Southern Hemisphere), which varies from experiment to experiment. $S$ is a parameter that allows a phase shift in the forcing of the two hemispheres of either 0 , if $S=0$, or half a period if $S=\pi$. The surface forcing profile given in Eq. 1 is representative of periodically changing winter temperatures which determine how much deep water is formed at high northern or southern latitudes. The phase lag $S=\pi$ reflects the fact that in the real world, the forcing in the two hemispheres is not necessarily in phase. For instance, the precessional orbital forcing causes mild winters in one hemisphere to coincide with severe winters in the other hemisphere (Hays et al. 1976). By varying $F_{\mathrm{H}}$ and $S$, we create a suite of experiments in which the northernmost temperature oscillates between values of $0^{\circ} \mathrm{C}$ and $4^{\circ} \mathrm{C}$ and the southernmost temperature oscillates between, respectively, $0^{\circ} \mathrm{C}$ and $4^{\circ} \mathrm{C}$, $1^{\circ} \mathrm{C}$ and $5^{\circ} \mathrm{C}$, and $3^{\circ} \mathrm{C}$ and $7^{\circ} \mathrm{C}$. The Northern Hemisphere
Table 2 Forcing periods (bold) in years and associated integration time (italics) in years

\begin{tabular}{llllll}
\hline $\mathbf{0 . 5}$ & $\mathbf{1}$ & $\mathbf{2}$ & $\mathbf{4}$ & $\mathbf{8}$ & $\mathbf{1 5}$ \\
4,000 & 4,000 & 4,000 & 4,000 & 4,000 & 4,000 \\
$\mathbf{3 0}$ & $\mathbf{6 0}$ & $\mathbf{1 2 0}$ & $\mathbf{2 5 0}$ & $\mathbf{5 0 0}$ & $\mathbf{1 , 0 0 0}$ \\
4,000 & 4,000 & 4,000 & 4,000 & 6,000 & 10,000 \\
$\mathbf{2 , 0 0 0}$ & $\mathbf{4 , 0 0 0}$ & $\mathbf{8 , 0 0 0}$ & $\mathbf{1 6 , 0 0 0}$ & $\mathbf{3 2 , 0 0 0}$ & \\
12,000 & 20,000 & 48,000 & 80,000 & 96,000 & \\
\hline
\end{tabular}

is therefore the dominant one in all our experiments, and the Southern Hemisphere is the subordinate one (except when the amplitude of the forcing is the same in both hemispheres). The forcing period $P$ is varied from 0.5 to 32,000 years.

In addition to the experiments using periodic forcing we perform an additional set of experiments where the surface forcing is kept temporally constant at the forcing extremes. The experiments with a temporally fixed surface forcing correspond to an oscillatory forcing with an infinite period and allow us to investigate the asymptotic response of the ocean circulation. The experiment nomenclature is such that the first letter refers to the nature of the run $(O$ : oscillating, S: steady; see Table 1), the first number refers to the maximum restoring temperature at the northernmost grid point in the Northern Hemisphere, the second number to the maximum restoring temperature at the southernmost grid point in the Southern Hemisphere, and an A is added if the forcing has a phase lag of $\pi$ between the two hemispheres.

Figure 1 shows the minimum and maximum restoring temperature for experiments $\mathrm{O} 4-4, \mathrm{O} 4-5, \mathrm{O} 4-4 \mathrm{~A}$ and $\mathrm{O} 4-$ $5 \mathrm{~A}$. Over one forcing period, the restoring temperature oscillates between these extreme profiles. Table 2 lists the 
Fig. 1 Maximum and minimum restoring temperature field in ${ }^{\circ} \mathrm{C}$ for experiments $\mathrm{O} 4$ 4, O4-4A O4-5, and O4-5A. In the $\mathrm{NH}$ the black and blue curves apply to all experiments, in the $\mathrm{SH}$ the green and red curves apply to O4-4 and O4$4 \mathrm{~A}$, the black and blue curves to O4-5 and O4-5A. During a forcing period, the restoring temperature field oscillates between the curves

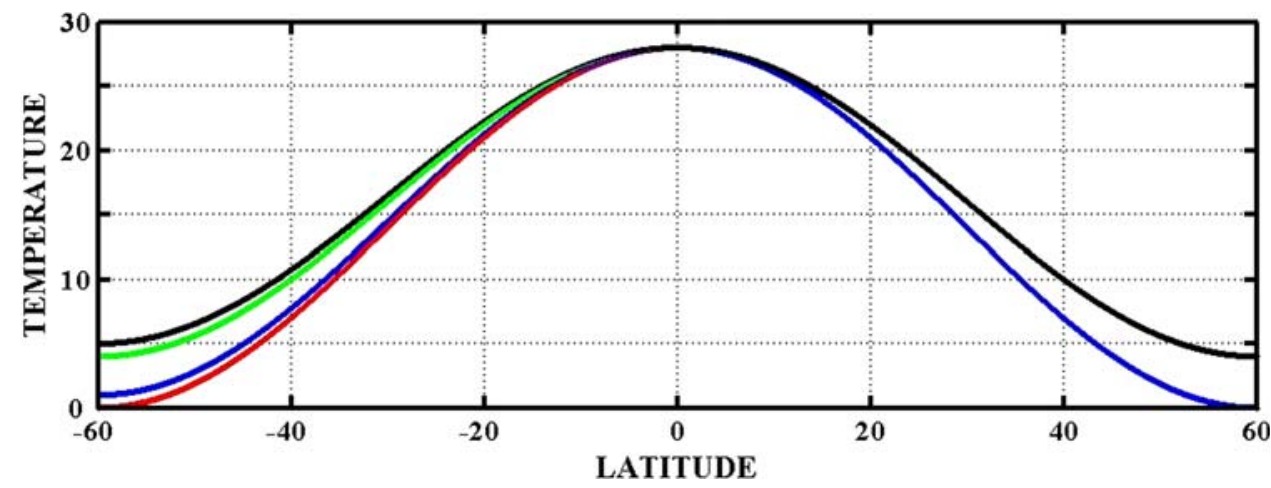

forcing periods used and the integration time for each of them.

\section{Asymptotic $(P \rightarrow \infty)$ forcing}

For experiments S0-1 and S4-5 the overturning has the same strength in the Southern Hemisphere, while in the Northern Hemisphere, the overturning is $0.7 \mathrm{~Sv}(1 \mathrm{~Sv}=$ $10^{6} \mathrm{~m}^{3} \mathrm{~s}^{1}$ ) stronger for $\mathrm{S} 4-5$. If the experiments with asymptotic forcing are any guide (i.e. the $\mathrm{S}$ experiments), the amplitude of the oscillations in the overturning should be very small for a very long period and zero lag. In agreement with Klinger and Marotzke (1999), the strength of the overturning cell in the dominant hemisphere is set in part by the dominant hemisphere's surface forcing but also by the subordinate hemisphere's surface forcing. Hence the value of the maximum overturning in the Northern Hemisphere is almost identical for experiments S0-4 and S0-5, 17.4 and $18.1 \mathrm{~Sv}$, respectively but is distinctively greater than for $\mathrm{S} 0-1$ (14 Sv). The value of the maximum overturning for experiment $\mathrm{S} 0-1$ is very close to that of $\mathrm{S} 4-5$, which suggests that the surface density difference between high northern and southern latitudes controls the strength of the overturning cells in both hemispheres, dominant and subordinate. This idea is supported by the fact that the overturning cells in both hemispheres have the same strength $(\sim 12 \mathrm{~Sv})$ when the forcing is symmetric about the equator, and this regardless of the lowest surface restoring temperature (Table 3, S0-0, S4-4).

Experiments S0-5 and S4-1 are the extremes between which experiment $\mathrm{O} 4-5 \mathrm{~A}$ oscillates. The difference in the overturning between $\mathrm{S} 0-5$ and $\mathrm{S} 4-1$ is $11.3 \mathrm{~Sv}$ for the Northern Hemisphere and $12 \mathrm{~Sv}$ in the Southern Hemisphere. These results suggest that for an experiment with a lag of half a period in the forcing between the two hemispheres at very long periods, there will be significant amplitudes in the oscillations, even in the subordinate hemisphere.

\section{Oscillatory runs}

\subsection{Spatial behaviour of the double hemisphere basin}

The forcing of the oscillatory runs is obviously more complex than that of the asymptotic runs, a complexity that is reflected in the evolution of the spatial structure of the circulation. The fundamental difference between $\mathrm{O} 4-5$ and

Table 3 Maximum overturning stream function after the spin up of the asymptotic (S) runs for a double hemisphere basin, in the Northern Hemisphere and the Southern Hemisphere

\begin{tabular}{lllcc}
\hline $\begin{array}{l}\text { Experiment } \\
\text { name }\end{array}$ & $\begin{array}{l}\text { Northernmost relaxation } \\
\text { temperature }\left({ }^{\circ} \mathrm{C}\right)\end{array}$ & $\begin{array}{l}\text { Southernmost relaxation } \\
\text { temperature }\left({ }^{\circ} \mathrm{C}\right)\end{array}$ & $\begin{array}{l}\text { Maximum overturning } \\
\text { in NH (Sv) }\end{array}$ & $\begin{array}{l}\text { Maximum overturning } \\
\text { in SH }(\mathrm{Sv})\end{array}$ \\
\hline S0-0 & 0 & 0 & 11.8 & 11.8 \\
S0-1 & 0 & 1 & 14 & 9.3 \\
S0-4 & 0 & 4 & 17.4 & 6 \\
S0-5 & 0 & 5 & 18.1 & 5 \\
S4-1 & 4 & 1 & 6.8 & 16.7 \\
S4-4 & 4 & 4 & 12.1 & 12.1 \\
S4-5 & 4 & 5 & 14.8 & 9.3 \\
\hline
\end{tabular}

The name of the experiments contains two numbers, $\mathrm{Si}-\mathrm{j}$, i indicating the northernmost restoring temperature and $\mathrm{j}$ the southernmost restoring temperature. In the Northern hemisphere, the positive sign indicates a clockwise circulation cell whereas in the Southern Hemisphere, the positive sign indicates a anticlockwise circulation cell. The strength of each cell is given in Sverdrups 
Fig. 2 Restoring temperature in ${ }^{\circ} \mathrm{C}$ in the oscillatory runs for a forcing period of 2,000 years, for the Northern Hemisphere (a) and the Southern Hemisphere (b). The blue curves are the restoring temperature at $60^{\circ}$ latitude, the green at $30^{\circ}$ and the red at the equator. The solid lines are for experiment $\mathrm{O} 4-5$ and the dashed line for experiment $\mathrm{O} 4-5 \mathrm{~A}$. Note that for experiment $\mathrm{O} 4-5 \mathrm{~A}$, the dashed and solid lines are overlaid in the Northern Hemisphere


O4-5A is expected to be in the Southern Hemisphere, which is in phase with the Northern Hemisphere for experiment $\mathrm{O} 4-5$ but out of phase for experiment O4-5A (Fig. 2). With a $\pi$ lag in the forcing, the meridional overturning cells in the double hemisphere basin respond qualitatively in a similar fashion for all forcing periods (not shown). The differences in behaviour between the forcing periods above 10 years are predominantly quantitative; in other words, the spatial pattern remains the same but the maximum intensity of the cells varies (for instance, for a forcing period of 2,000 years the maximum overturning in the Northern Hemisphere is $17 \mathrm{~Sv}$, for 16,000 years it is $9 \mathrm{~Sv}$ ). Consequently, any forcing period will give a good indication of the generic behaviour of the basin during a forcing cycle. In this section, the evolution of the circulation over one representative forcing period, 2000 years, is examined. Notice that year zero is defined such that the northernmost forcing temperature is highest.

For a forcing period of 2,000 years and lag 0, both experiments have an overturning stream function that displays two cells in either hemisphere (Fig. 3). The main difference between the two runs is that in $04-5 \mathrm{~A}$, the growth and decay of each cell is in antiphase and as a result, the southern cell at its maximum intensity invades the northern hemisphere (Fig. 3 panel c).

In terms of potential temperature, the main difference between $\mathrm{O} 4-5$ and $\mathrm{O} 4-5 \mathrm{~A}$ is that in the latter experiment, the deep water formed in the Southern Hemisphere penetrates much deeper (beyond 3,500 m). Furthermore, the continuous formation of deep water leads to a basin-wide up welling of cold water and means that the deep ocean is colder.

\subsection{General behaviour for all forcing periods}

The time series of maximum overturning in both hemispheres for experiment O4-5 (Fig. 4) show a behaviour similar to what can be found in the single hemisphere experiment (Lucas et al. 2005), with a jump in amplitude in the overturning response between the forcing period of 8 years and the forcing period of 15 years. Furthermore, as in Lucas et al. (2005), the overturning response is non linear and the phase shift between the forcing and the response varies with the forcing period. An in depth analysis of these points is beyond the scope of this paper but some elements of discussion can be found in Lucas et al. (2005). Both hemispheres have a period for which the amplitude of the oscillations is at a maximum, in effect displaying a resonance like behaviour. The main difference between the two hemispheres lies in the strength and amplitude of the oscillations in the overturning. The oscillations in the Northern Hemisphere have a maximum amplitude of $17 \mathrm{~Sv}$ and are thus far stronger than in the Southern Hemisphere where they have a maximum amplitude of $7 \mathrm{~Sv}$. Perhaps as a consequence, the Southern Hemisphere seems almost to have reached its asymptotic behaviour for a forcing period of 32,000 years as the amplitude of the oscillations is less than $1 \mathrm{~Sv}$.

For experiment O4-5A (Fig. 5), once again both hemispheres seem to follow the generic behaviour of a 

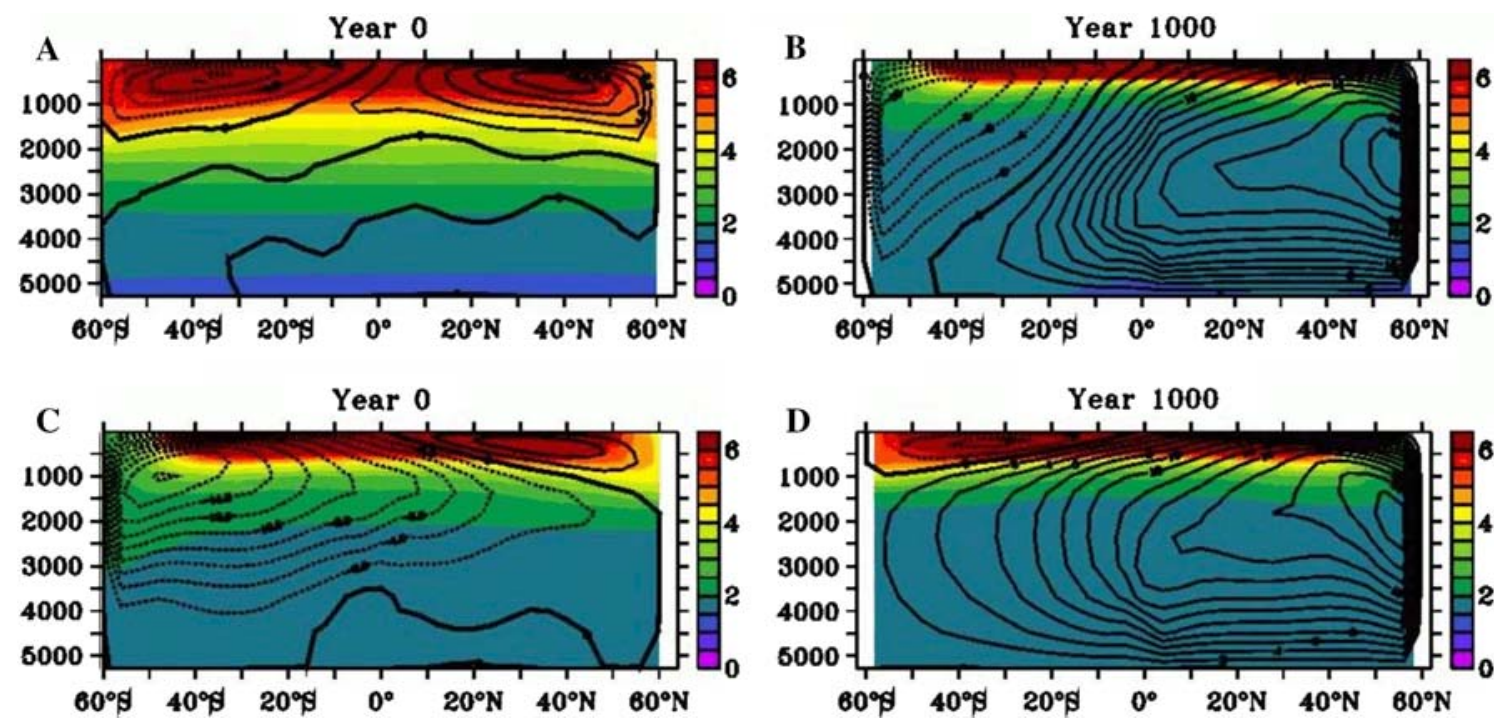

Fig. 3 Zonally averaged temperature in ${ }^{\circ} \mathrm{C}$ (colour shading) and MOC in Sv (contours, $\mathrm{CI}=2 \mathrm{~Sv}$ for two snapshots of a forcing period of 2,000 years for $\mathrm{O} 4-5(\mathbf{a}, \mathbf{b})$ and $\mathrm{O} 4-5 \mathrm{~A}(\mathbf{c}, \mathbf{d})$

Fig. 4 Maximum overturning stream function $(S v)$ for experiment $\mathrm{O} 4-5$, in the Northern Hemisphere (a) and the Southern Hemisphere (b). Once equilibrium is reached, the forcing period is doubled. The range in forcing period is 6 month to 32,000 years
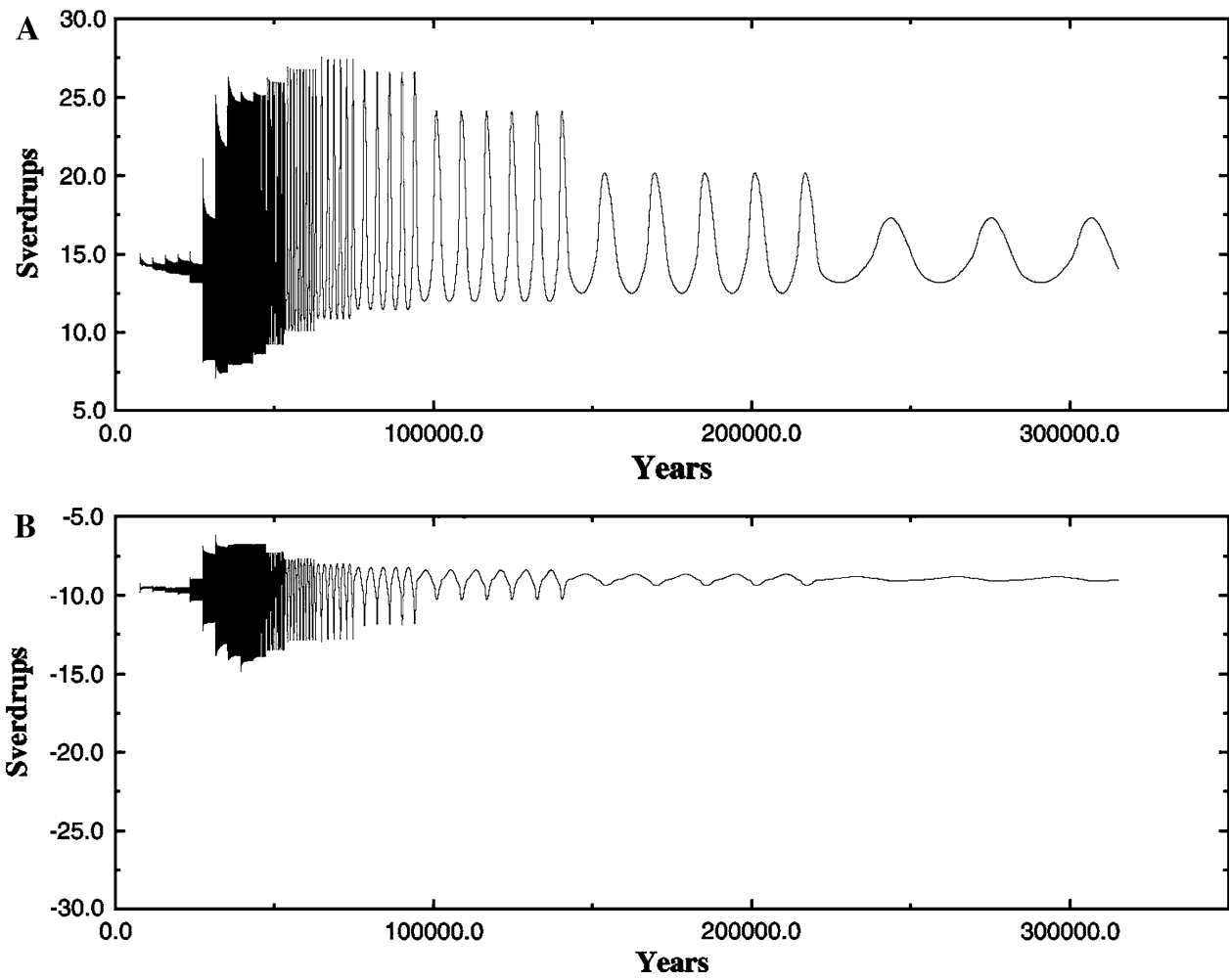

single hemisphere basin in that the jump between forcing periods of 8 and 15 years is present and that there is a period for which the overturning has a maximum amplitude. As in the single hemisphere set up (Lucas et al. 2005), the response of the overturning in both hemisphere is non linear and the phase lag between the forcing and the overturning response varies with the forcing period. There is however no simple relationship linking the forcing period to the lag.
There are some striking differences between the overturning curves in the two sets of experiments, especially for long forcing periods. In the Northern Hemisphere, the amplitude is generally larger than for the O4-5 experiment and the strength of the overturning reaches an absolute minimum, which is constant for all periods above 250 years.

In the Southern Hemisphere, the amplitude is far larger than in the $\mathrm{O} 4-5$ experiment (14 Sv against a maximum of 
Fig. 5 Maximum overturning stream function $(S v)$ for experiment $\mathrm{O} 4-5 \mathrm{~A}$, in the Northern Hemisphere (a) and the Southern Hemisphere (b). Once equilibrium is reached, the forcing period is doubled. The range in forcing period is 6 month to 32,000 years
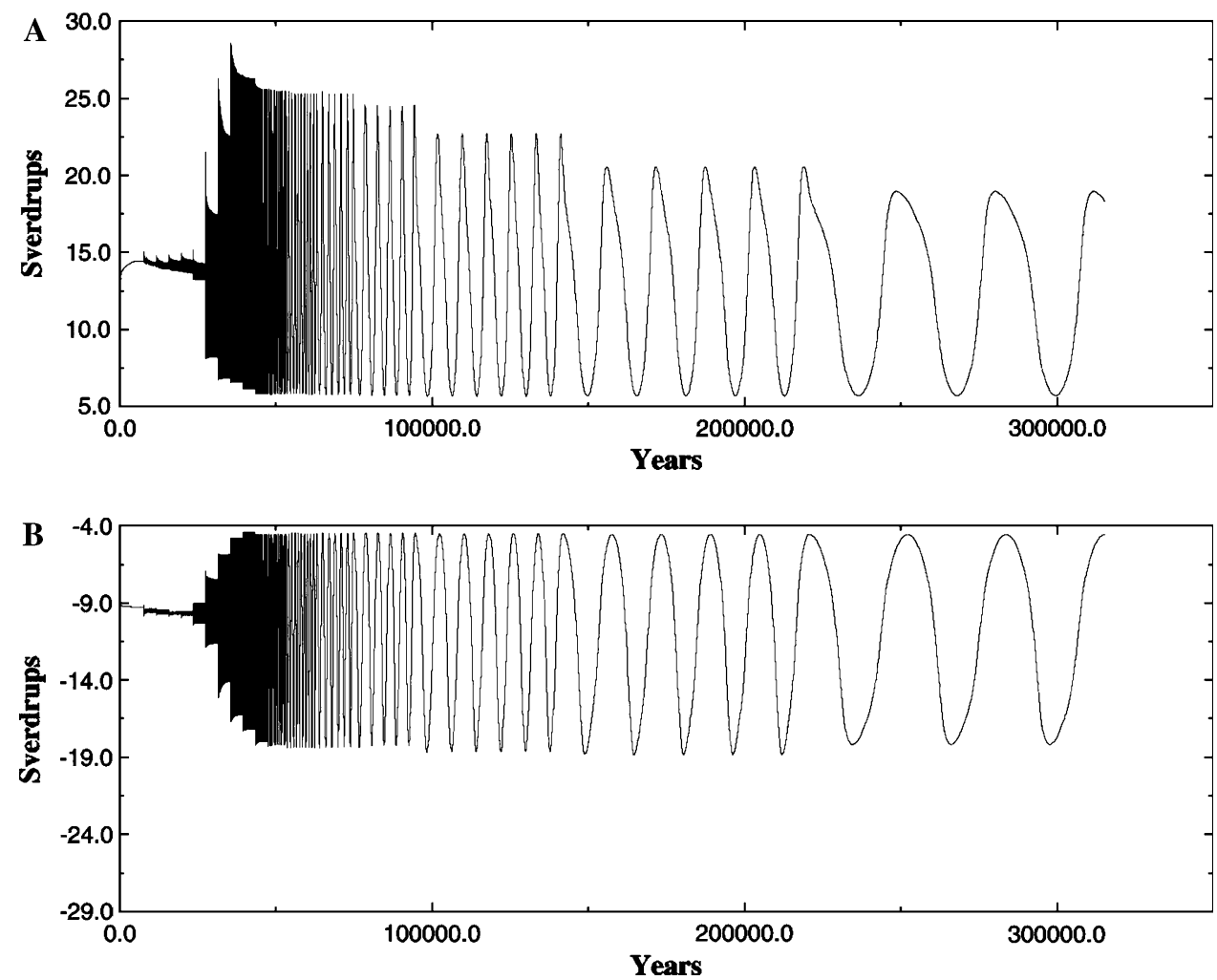

$7 \mathrm{~Sv}$ ) and as in $\mathrm{O} 4-5$, the absolute minimum of the strength of the overturning is constant for periods above 60 years. The amplitude is also fairly constant, suggesting that the system is near equilibrium in the Southern Hemisphere. Table 4 shows that the higher the maximum temperature in the subordinate hemisphere, the greater the maximum value of the strength of the overturning is in the dominant hemisphere. Furthermore, the lower the minimum temperature in the subordinate hemisphere, the weaker the minimum strength of the overturning is in the dominant hemisphere.

In the experiments with a 0 lag forcing (O4-4 and $\mathrm{O} 4$ 5 ), the amplitude of the response of the overturning in both hemispheres first increases and then decreases as the experiment progresses through the increasingly longer forcing periods. Towards the very long forcing periods, the amplitude in the overturning decreases, as expected from the asymptotic behaviour described earlier.

In the experiments with lag $\pi(\mathrm{O} 4-4 \mathrm{~A}, \mathrm{O} 4-5 \mathrm{~A}, \mathrm{O} 4-7 \mathrm{~A})$, the overturning amplitude in the dominant hemisphere generally increases then decreases towards an overturning amplitude equal to that suggested by the asymptotic values (see Table 3, S0-5 and S4-1, for instance). The behaviour of the amplitude in the subordinate hemisphere is clearly dependent on its degree of subordination: the greater that is, the less likely the subordinate hemisphere has reached a resonance-like behaviour for the forcing periods examined. Indeed, in the last experiment of Table 4 (O4-7A), it is unclear whether or not the overturning has reached a resonance as its overturning amplitude is still increasing towards that suggested by the asymptotic runs. For the $\pi$ lag forcing, if the mean of the southernmost forcing value is increased but the range of the variability in the forcing kept the same (O4-4A, O4-5A, O4-7A), the maximum overturning amplitude in the dominant hemisphere increases and the resonance-like period decreases from 250 to 60 years. In the subordinate hemisphere, the amplitude of the overturning decreases when the southernmost forcing value is increased but the range of the forcing temperature is kept the same. The resonance-like period increases, going from 250 years to above 32,000 years. Note that the amplitude of the overturning in the Southern Hemisphere at very long periods is very close to that of the Northern Hemisphere at the same periods. The differences in the overturnings between the cells in each hemisphere are almost equal, as the asymptotic cases (Table 3, S0-5, S4-1).

\subsection{Deep water production}

One of the most striking aspects of our experiments is the presence of oscillations of half the forcing period in the temperature signal in both hemispheres for O4-5A (Fig. 6). This occurs for forcing periods of a century and longer and is a consequence of the deep water production. For the shorter periods, there are only small differences between 
Table 4 Summary of the main features for each of the oscillating experiments

\begin{tabular}{|c|c|c|c|c|c|c|c|c|c|c|}
\hline \multirow[t]{2}{*}{ Experiment } & \multicolumn{5}{|c|}{ Northern Hemisphere } & \multicolumn{5}{|c|}{ Southern Hemisphere } \\
\hline & Restoring & $\Phi_{\min }(\mathrm{Sv})$ & $\Phi_{\max (\mathrm{Sv})}$ & $A_{\max (\mathrm{Sv})}$ & $P_{\text {Amax (years) }}$ & Restoring & $\Phi_{\min }(\mathrm{Sv})$ & $\Phi_{\max (\mathrm{Sv})}$ & $A_{\text {ma }}(\mathrm{Sv})$ & $P_{\text {Amax (years) }}$ \\
\hline O4-4 & $0-4$ & 6 & 22 & 13 & 2,000 & $0-4$ & 6 & 22 & 13 & 2,000 \\
\hline O4-5 & $0-4$ & 7.5 & 27 & 17 & 125 & $1-5$ & 7 & 14 & 7 & 125 \\
\hline $\mathrm{O} 4-4 \mathrm{~A}$ & $0-4$ & 4.8 & 22.5 & 17.3 & 250 & $0-4$ & 4.8 & 22.5 & 17.3 & 250 \\
\hline O4-5A & $0-4$ & 6 & 27 & 20 & 125 & $1-5$ & 4.8 & 18.5 & 14 & 16,000 \\
\hline O4-7A & $0-4$ & 8 & 31.7 & 23.2 & 60 & $3-7$ & 3.6 & 15.5 & 11.9 & 32,000 \\
\hline
\end{tabular}

$\Phi_{\min }$ is the absolute minimum value that the overturning reaches, $\Phi_{\max }$ the absolute maximum value that the overturning reaches, $\mathrm{A}_{\max }$ the maximum amplitude that the overturning reaches and $\mathrm{P}_{\mathrm{Amax}}$ the period at which the maximum amplitude in the overturning occurs. Note that the overturning is clockwise in the Northern Hemisphere and anti-clockwise in the Southern Hemisphere

Fig. 6 Zonal mean potential temperature at $2,000 \mathrm{~m}$ for both hemispheres at $60^{\circ}$ in experiments $\mathrm{O} 4-5$ (black) and O4-5A (red). Curves for the Northern Hemisphere are dashed, and curves for the Southern Hemisphere are solid. The $x$-axis is time in fractions of a period and the $y$-axis is temperature in ${ }^{\circ} \mathrm{C}$
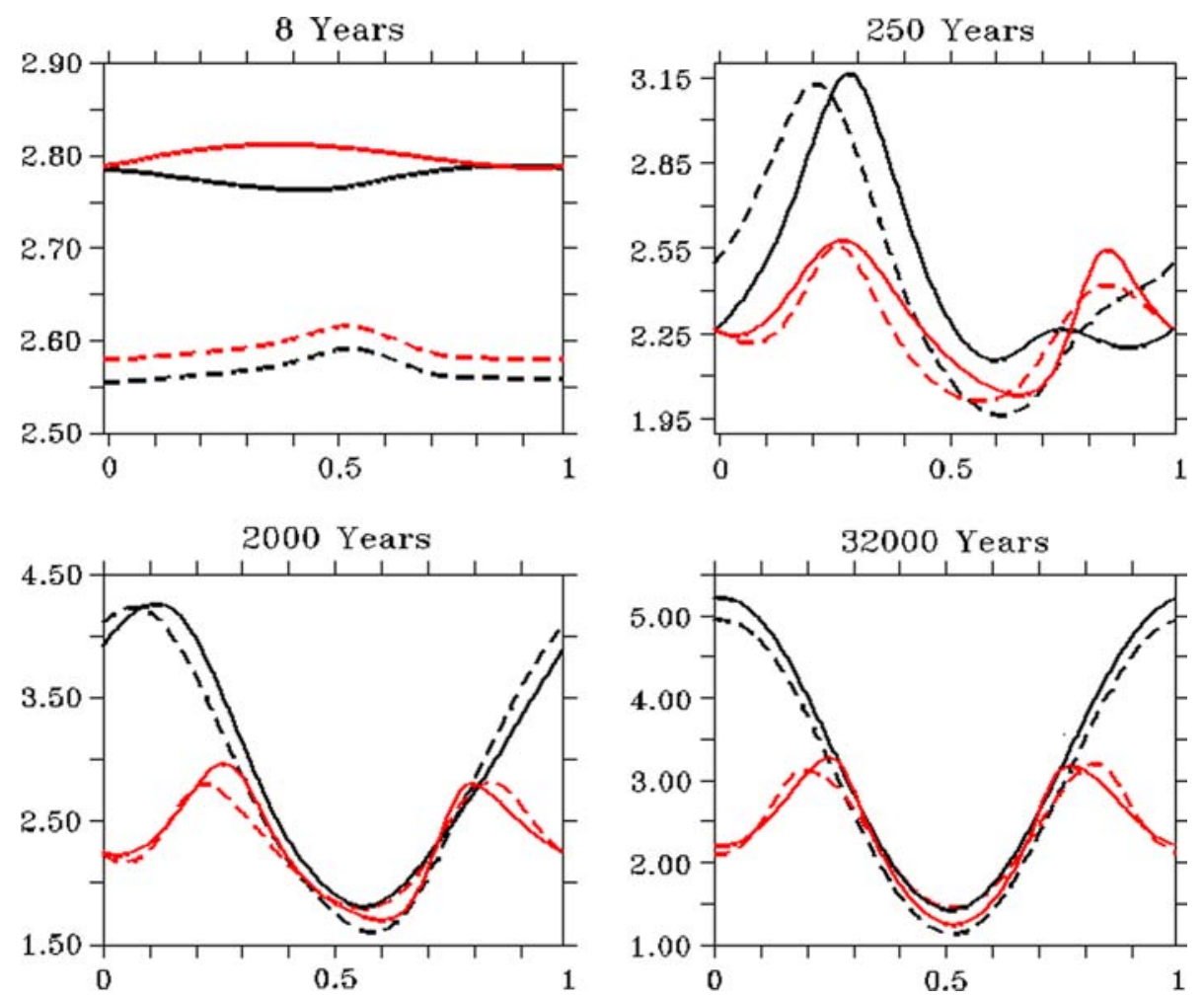

O4-5 and $\mathrm{O} 4-5 \mathrm{~A}$, both in terms of the overturning behaviour and the deep ocean temperature (Fig. 6). Clearly, not enough of the forcing signal is captured to induce a substantial response from the ocean circulation. As a result, oscillations of the overturning and of the temperature are very small. The temperatures are slightly higher in the subordinate hemisphere than in the dominant hemisphere.

For periods of a century and longer, differences between the symmetrical and asymmetrical experiments (O4-5 and O4-5A) become more pronounced. For the $\pi$ lag forcing, the two sources of deep water are out of phase, resulting in near continuous production of deep water (Fig. 3c, d). This means that the lower levels never become warm (relative to the 0 lag experiment), even for the long periods (Fig. 6). As the deep waters in one hemisphere start to warm, cold water from the other hemisphere is advected in and, as a result, the temperature of the deep water decreases again. The temperature profiles oscillate with a period half that of the forcing, in both hemispheres. The permanent presence of cold deep water allows strong stratification in the hemisphere (Fig. 7) where the maximum warming of the surface waters coincides with cold deep temperatures. This strong stratification leads to a very weak overturning explaining the lower minimum strength of the overturning cell found in both hemispheres for experiment O4-5A (Fig. 5). In the Northern Hemisphere the lower minimum overturning strength largely explains the higher amplitudes of the overturning as only small changes are found for the maximum strength of the overturning cell (Figs. 4, 5). In 
Fig. 7 Schematics of the stratification when long periodic asymmetric $(\mathbf{a}-\mathbf{c})$ or symmetric (d-f) forcing is applied. Contours illustrate isotherms and arrows show deep water formation in the Northern and Southern Hemispheres (NDW, SDW), mixing and upwelling. a, c illustrate the high stratification that develops in the warmer hemisphere for the asymmetric forcing compared to the symmetric forcing $(\mathbf{d}, \mathbf{f})$. The figure can also be used to illustrate the "half-a-period" temperature signal seen in the deep temperatures $(\mathbf{a}, \mathbf{c})$ : for long forcing periods

(asymmetric) the coldest deep temperatures occur when either NDW or SDW is vigorous (the periodicity of that is half that of the forcing period). For symmetric forcing the coldest deep temperatures occur when both NDW and SDW are strong (d). This happens with the same periodicity as the surface forcing
A
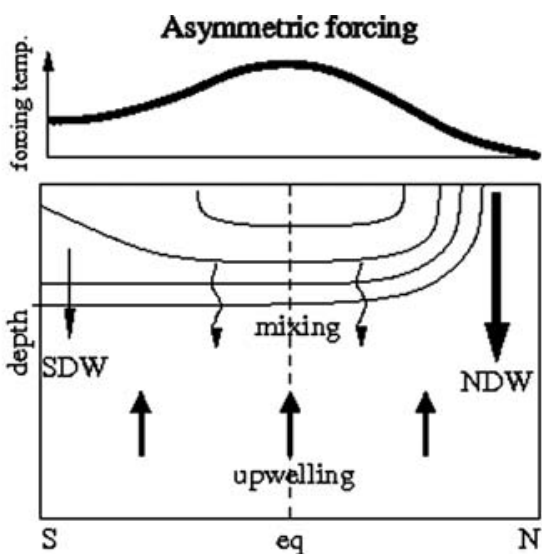

B
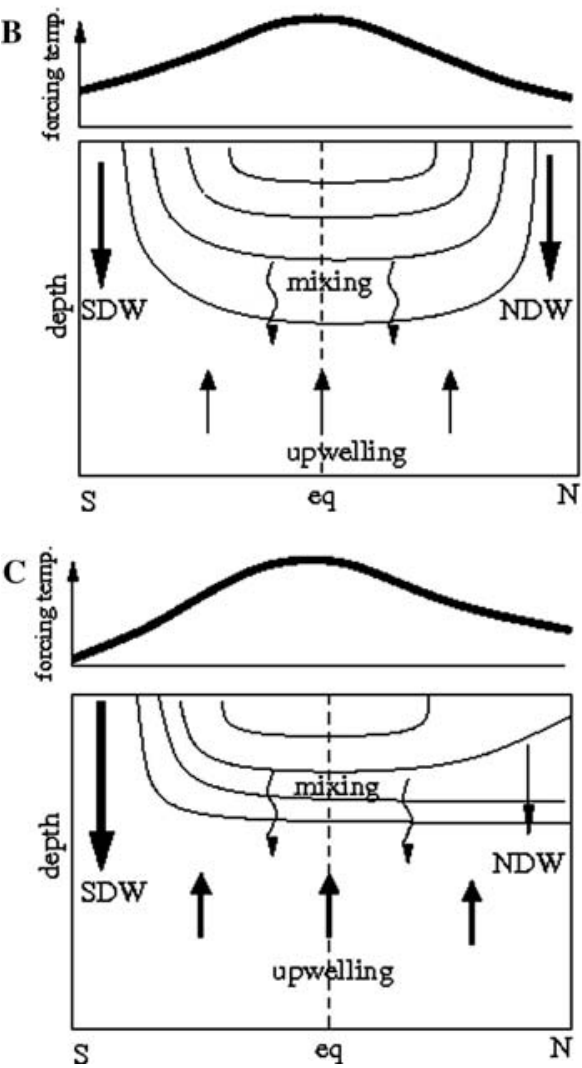

D
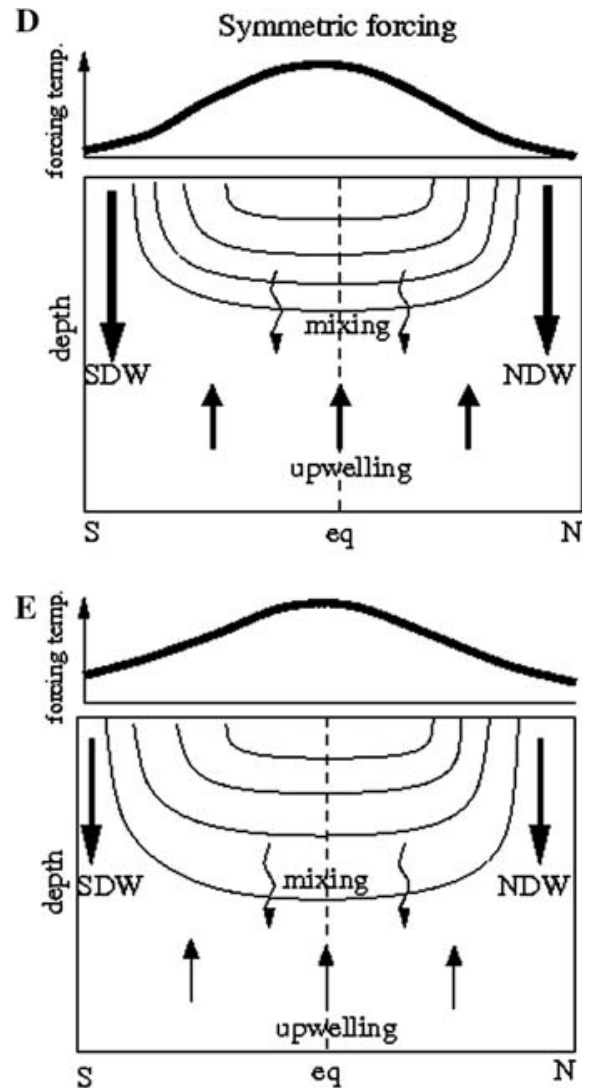

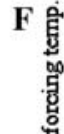

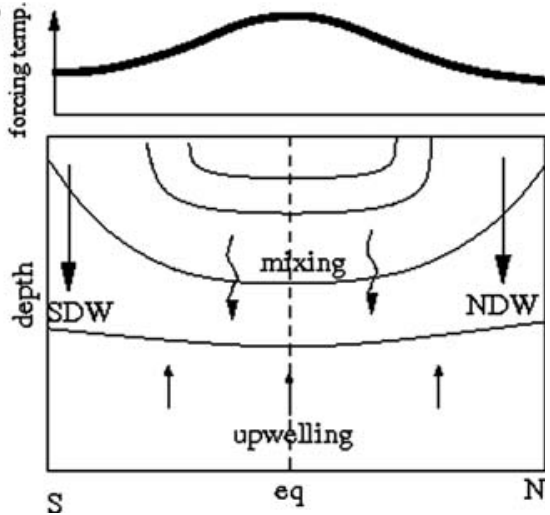

the Southern Hemisphere both a decrease in the minimum strength of the overturning cell and an increase in the maximum strength of the overturning cell contribute to the larger amplitude of the overturning response. This happens because in $\mathrm{O} 4-5 \mathrm{~A}$, each hemisphere is in turn dominant or subordinate during a forcing cycle. As the forcing is on average only $1{ }^{\circ} \mathrm{C}$ warmer at high southern latitudes in experiment $\mathrm{O} 4-5 \mathrm{~A}$, this allows for a clear dominance of the Southern Hemisphere when the southern forcing values are at their coldest (and the northern at their warmest). This is reflected in the higher maximum of the strength of the southern overturning cell in O4-5A compared with O4-5 (Figs. 4, 5, Table 4).
The alternation of the dominant hemisphere contributes to a decoupling of the surface and bottom ocean for long forcing periods. The surface temperature in each hemisphere is controlled by the forcing in that hemisphere whereas the bottom temperature is controlled by the forcing in both hemispheres as either the northern or southern overturning cell controls the interhemispheric exchange of water masses at depth. This leads to a situation where the surface reaches a maximum when the bottom reaches a minimum. For instance, the maximum surface to bottom temperature difference in the Northern Hemisphere at $60^{\circ} \mathrm{N}$ is $1.42^{\circ} \mathrm{C}$ in the O4-5 experiment against $2.42^{\circ} \mathrm{C}$ in the $\mathrm{O} 4-5 \mathrm{~A}$ experiment. This is why, for the asymptotic case mentioned in Sect. 3, the 
strength of the overturning in each hemisphere depends partly on the interhemispheric density gradient as this will, in effect, set the surface to bottom temperature difference. This surface to bottom temperature difference determines the strength of the overturning, which means that a fairly weak temperature difference between the high northern and high southern latitudes leads to significant differences in terms of the strength of the overturning in each hemisphere, as noted by Marotzke and Klinger (2000).

\subsection{Resonance-like behaviour}

The resonance-like behaviour has the same fundamental mechanisms as that of a single hemisphere basin (Lucas et al. 2005). However, some elements are unique to the double hemisphere set-up. In forcing conditions with no lag, both hemispheres behave almost independently except that the deep water temperature in either hemisphere shows some response to the other in the form of slight phase and amplitude shifts (Fig. 6). As the forcing period is increased, the temporal evolution of the deep water temperature becomes similar in both hemispheres (Fig. 6). The fact that for periods of a few centuries and above, the minimum bottom temperature in either hemisphere is virtually the same (i.e., that there is in effect only one source of deep water, namely that produced in the Northern Hemisphere) means that the maximum stratification in the Southern Hemisphere is stronger than that of the Northern Hemisphere and the minimum overturning in the Southern Hemisphere is smaller (Fig. 4). Similarly, the minimum stratification is stronger in the Southern Hemisphere and therefore, the maximum overturning over a cycle is smaller.

In the experiments with half a period lag in the forcing, the presence of two sources of deep water (Fig. 7) also has significant impact on the resonance-like behaviour of the system. Table 4 shows that, as the average temperature increases (O4-4A, O4-5A, O4-7A), the period for which the maximum amplitude occurs becomes smaller. This is similar to what happens in a single hemisphere configuration when the vertical diffusion is increased. In that set-up, the resonance occurs when a substantial part of the forcing signal is captured by the surface ocean but the diffusion cannot keep up with the changes in the surface and as a result, the water column is either weakly stratified or strongly stratified (Lucas et al. 2005).

In the double hemisphere experiment, the mechanism is slightly different. The second source of deep-water leads to weaker minimum stratification in the dominant hemisphere than in the single-hemisphere case. Indeed, when the surface water's temperature is at a minimum, the minimum bottom temperature is higher than in the single hemisphere case (weaker stratification, Fig. 7). Conversely, when the surface waters are at their warmest in the dominant hemisphere, the deep temperature is lower than in the single hemisphere case and as a result, the overturning will be weaker (stronger stratification, Fig. 7). Thus, the maximum overturning in the double hemisphere case is greater than in the single hemisphere case and the minimum overturning is weaker. This leads to a greater amplitude in the overturning in the dominant hemisphere compared to the single hemisphere case.

In summary, the presence of a second deep water source favors the occurrence of both very stable and very unstable stratifications (high and low surface to bottom temperature differences), each at opposite extremes of the forcing cycle. As shown in Table 4, the period with the maximum response varies predominantly because of the changes in the maximum overturning value. The resonance shifts towards the smaller period mainly because the absolute maximum shifts towards them. This is because the minimum overturning during a forcing cycle very quickly reaches a value close to the absolute minimum overturning for the experiment. Furthermore, once the absolute minimum overturning has been reached by the minimum overturning over a cycle, the value of minimum overturning during a forcing cycle remains constant for subsequent forcing periods (Fig. 5). The maximum overturning during a cycle shows much more variability. Hence the behaviour of the resonance is principally controlled by the minimum stratification that occurs during a forcing cycle. This occurs when a substantial part of the forcing signal is captured but not transmitted fast enough by diffusion to the deep ocean. The higher the average forcing temperature, the higher the bottom temperature becomes. As a result, the water column is less stratified. This means that a smaller forcing period is needed to create the minimum stratification since less of the forcing signal will need to be captured. The absolute overturning maximum occurs when the surface to bottom temperature difference reaches an absolute minimum. As is shown in Fig. 8, for O4-4A, the minimum temperature difference is still decreasing as the period increases from 8 to 250 years. For O4-5A and O4$7 \mathrm{~A}$, the minimum in the surface to bottom temperature difference decreases from 8 to 60 years but increases from 60 to 250 years, indicating that the absolute minimum occurs for a period between 60 and 120 years. Furthermore, the range in the surface to bottom temperature difference for these two experiments has also reached a maximum for a period between 60 and 250 years, indicating that the resonance period is somewhere in between, as is shown in Table 4 .

\section{Discussion and summary}

\subsection{Discussion}

Our experiments have demonstrated the complexity of the response of a double hemisphere ocean basin to a very 
Fig. 8 Surface to bottom temperature difference at $60^{\circ}$ (zonally averaged) for $\mathrm{O} 4-4 \mathrm{~A}$ (black), O4-5A (red) and O47A (green). The $y$-axis is temperature in ${ }^{\circ} \mathrm{C}$ and the $x$-axis is time in fractions of a period
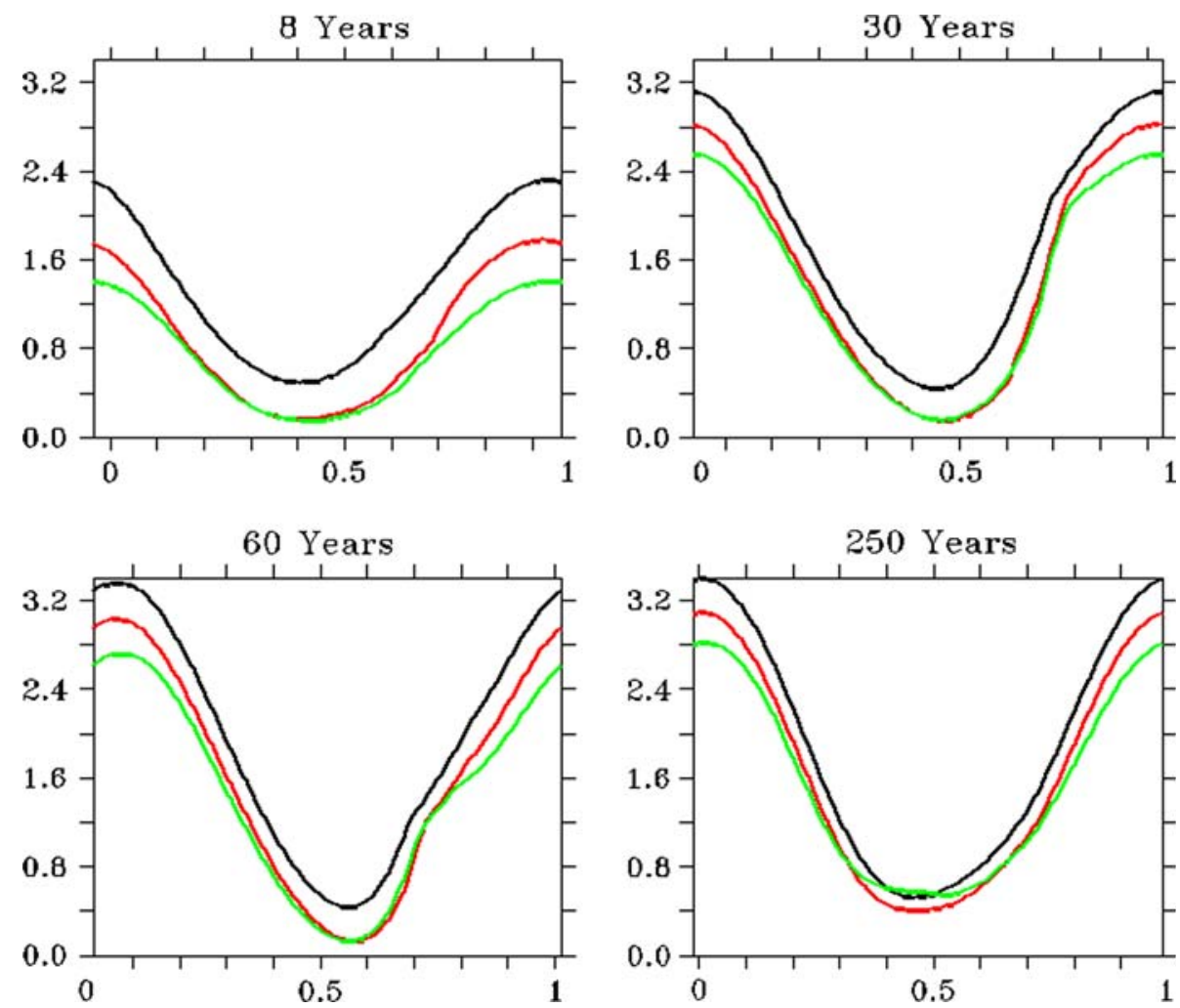

simple oscillatory buoyancy forcing. The results emphasise the critical part played by the lag in the forcing between the hemispheres, in determining the amplitude of the response in the overturning, particularly for long forcing periods. Indeed, when there is no lag, the amplitude of the overturning response decreases substantially for very long forcing periods (4,000 years and above, Fig. 9), in a way similar to what happens for a single hemisphere basin (Lucas et al. 2005). For a lag of half the forcing period, the decrease in the amplitude is far less pronounced (Fig. 9), in stark contrast to what was found for the no lag situation and in Lucas et al. (2005). In fact, the asymptotic behaviour (Table 3) suggests that these oscillations would persist for an infinite forcing period for the half period lag in the forcing. The strength of the amplitude of those oscillations for the lag of half a period stems from the presence of two sources of deep water, which cause the water column to become either strongly stratified leading to a weak overturning, or weakly stratified leading to a strong overturning (Fig. 7). This result agrees with the conclusions of Marotzke and Klinger (2000) who stated that the export rate of NADW is controlled by the mixing and upwelling in the rest of the world ocean. Indeed, the present study has clearly shown that what happens in the Southern Hemisphere has a profound impact on the Northern Hemisphere deep water production, even when the Northern Hemisphere forcing is substantially dominant (experiment O47A).

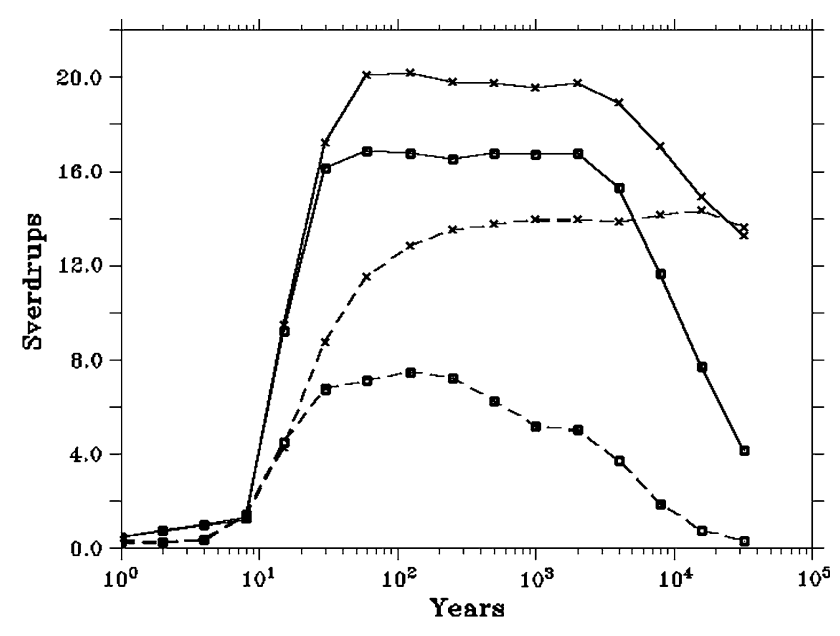

Fig. 9 Amplitude of oscillation against forcing periods. The dashed lines are for the southern hemisphere, the solid line the northern hemisphere. Crosses indicate the values of the O4-5A run, squares values of the $04-5$ run

In the experiments with lag $\pi$ and forcing periods of centuries and longer, we have consistently found temperature variations in the deep ocean with a period of half the forcing period. This occurs because twice during a forcing cycle, one or the other hemisphere is cold enough at the high-latitude surface to dominate deepwater formation, including export of deepwater to the subordinate hemisphere (Fig. 7). These results have some important implications when one considers the precessional orbital 
forcing of climate variations. The precessional forcing occurs on a 22,000-year cycle, which results from the combination of one forcing cycle of 19,000 years and one of 23,000 years. The precessional cycle strengthens or weakens the seasonal difference between the hemispheres by determining how close to the perihelion or aphelion of the Earth's orbit the solstices occur (e.g., Ruddiman 2001). At one of its extremes, the winters in one hemisphere are very cold and the summers very hot (strong seasonal difference) while at the other, the winters and summers in one hemisphere are mild (weak seasonal difference). Crucially, when one hemisphere has a strong seasonal contrast, the other has a weak one. Hence when we have a warm winter in the Northern Hemisphere, we will have a very cold winter in the Southern Hemisphere and vice versa. If we consider that the forcing we apply is equivalent to a winter forcing, when deep water production occurs, then our results suggest that the precession forcing can strongly influence the MOC. In our study, the experiments with a half period lag in the forcing between the Northern and Southern Hemispheres (O4-4A, O4-5A) provide the best insight into how the ocean could respond to precessional forcing. The results clearly show that for a forcing period of 22,000 years (in between 16,000 and 32,000 years), the response of the ocean would still be significant, with an amplitude of at least $10 \mathrm{~Sv}$ in the subordinate hemisphere (and greater in the dominant) if the amplitude of the forcing was $4^{\circ} \mathrm{C}$. This contrasts with what was found for a single hemisphere setup (Lucas et al. 2005), where the oscillations of the overturning at very long periods were weak. It is also markedly different from what Lorenz and Lohmann (2004) found in their simulations with a coupled model using an acceleration technique. Indeed, their approach yielded a quasi steady overturning circulation (roughly $20 \mathrm{~Sv}$ ), with no low frequency oscillations.

Our simulations, although performed with a full ocean general circulation model are highly idealized and the grid resolution is coarse, so extrapolation to the real world must done with caution. In particular, the issue of wind forcing and freshwater forcing is critical, However, Lucas et al. (2005) showed that wind driven circulation has only a minor impact on the results.

With regards to the freshwater forcing, the situation is somewhat more complicated. Dijkstra and Weijer (2003) show that the principal impact of the freshwater forcing under symmetrical forcing conditions is to favor the northern hemisphere sinking solution. Indeed, they state that four elements favor the northern sinking solution in the Atlantic: freshwater forcing, continental geometry, wind forcing and the presence of the Antarctic Circumpolar Current (ACC). In our study, this suggests that the 4-5 and 4-5A experiments are the most realistic as the buoyancy forcing in these situation favors the northern hemisphere sinking solution. A simulation identical to O4-5A was performed with the presence of an ACC and the results were virtually identical to that of O4-5A (not shown), indicating that our results are robust to the addition of an ACC. Finally, our experiments also do not have a seasonal cycle but the response of the circulation to a yearly forcing cycle only (i.e. a forcing period of one year) is very weak. This suggests that adding a seasonal cycle would add very little. Indeed, it is highly unlikely that a seasonal cooling would outweigh the longer term forcing. Our results therefore can provide some valuable insight into the processes at work in the real world. They suggest an explanation for the palaeo results that have described a 10,000-year cycle, very close to the halfprecession time scale, in the palaeo proxy record of the North Atlantic (Turney et al. 2004). Hence, the 10,000year-cycle found in the proxy record could stem from oscillations in the forcing due to the variation in the Earth precession.

\subsection{Summary}

We have shown that adding a subordinate Southern Hemisphere basin can profoundly alter the behaviour of the circulation in the Northern Hemisphere. With constant forcing, our results confirm that the strength of the overturning is controlled by the difference between the northern and southern high latitude forcing. For an oscillatory forcing, the behaviour of the circulation differs from that of a single hemisphere set-up (Lucas et al. 2005), particularly when the forcing in the Southern Hemisphere lags that of the Northern Hemisphere by half a period. In this case at least one of the two deep water sources (northern or southern source) is always active. The continuous supply of deep water cools the deep ocean and increases the maximum stratification that occurs during a forcing cycle. This in turns leads to a much greater amplitude in the oscillatory response of the meridional overturning circulation, particularly for long forcing periods (2,000 years and above). The impact of having a phase lag of half a period in the forcing on the Southern Hemisphere is even more pronounced; it leads to a dramatic increase in the amplitude of the oscillations of the meridional overturning stream function, with a range that is of the same order as that of the meridional overturning stream function in the dominant hemisphere. The phase lag also leads to a deep temperature signal in both hemispheres with a period of half that of the forcing. As our forcing with a phase lag of half a period between the hemispheres reflects winter forcing variations during a precessional cycle, we suggest the mechanism represented in our model as an explanation for the halfprecessional cycle that has been observed in palaeo data. 
Open Access This article is distributed under the terms of the Creative Commons Attribution Noncommercial License which permits any noncommercial use, distribution, and reproduction in any medium, provided the original author(s) and source are credited.

\section{References}

Biastoch A, Böning CW, Getzlaff J, Molines J-M, Madec G (2008) Mechanisms of interannual-decadal variability in the meridional overturning circulation of the mid-latitude North Atlantic Ocean. J Clim 21:6599-6615. doi:10.1175/2008JCLI2404.1

Bjornsson H, Toggweiler JR (2001) The climatic influence of Drake Passage. In: The oceans and rapid climate change: past, present, and future. Geophysical monograph 126, American Geophysical Union, Washington, DC, pp 243-259

Cunningham SA, Kanzow T, Rayner D, Baringer MO, Johns WE, Marotzke J, Longworth HR, Grant EM, Hirschi JJM, Beal LM, Meinen CS, Bryden HL (2007) Temporal variability of the Atlantic meridional overturning circulation at $26^{\circ} \mathrm{N}$. Science 317:935-938

Dansgaard W, Johnsen SJ, Clausen HB, Dahl-Jensen D, Gundestrup NS, Hammer CU, Hvidberg CS, Steffensen JP, Sveinbjörnsdottir AE, Jouzel J, Bond G (1993) Evidence for general instability of past climate from a 250-kyr ice-core record. Nature 364:218-220

Delworth TL, Greatbatch RJ (2000) Multidecadal thermohaline circulation variability driven by atmospheric surface flux forcing. J Clim 13:1481-1495

Delworth TL, Manabe S, Stouffer RJ (1993) Interdecadal variations of the thermohaline circulation in a coupled ocean-atmosphere model. J Clim 6:1993-2011

Dijkstra HA, Weijer W (2003) Stability of the global ocean circulation: the connection of equilibria in a hierarchy of models. J Mar Res 61:725-743

Ganachaud A, Wunsch C (2000) Improved estimates of global ocean circulation, heat transport and mixing from hydrographic data. Nature 408:453-457

Gent PR, McWilliams JC (1990) Isopycnal mixing in ocean circulation models. J Phys Oceanogr 20:150-155

Griffies SM (1998) The Gent-McWilliams skew flux. J Phys Oceanogr 28:831-841

Hays J, Imbrie J, Shackleton N (1976) Variations in the earth's orbit: pacemaker of the ice ages. Science 194:1121-1132

Heinrich H (1988) Origin and consequences of cyclic ice rafting in the Northeast Atlantic Ocean during the past 130, 000 years. Quat Res 29:142-152

Hirschi JJ-M, Killworth PD, Blundell JR (2007) Subannual, seasonal and interannual variability of the North Atlantic meridional overturning circulation. J Phys Oceanogr 37(5):1246-1265

Huybers P, Curry W (2006) Links between annual, Milankovitch, and continuum temperature variability. Nature 441:329-332

Kanzow T, Cunningham SA, Rayner D, Hirschi JJM, Johns WE, Baringer MO, Bryden HL, Beal LM, Meinen CS, Marotzke J
(2007) Flow compensation associated with the meridional overturning. Science 317:938-941

Klinger BA, Marotzke J (1999) Behavior of double hemisphere thermohaline flows in a single basin. J PhysOceanogr 29:382 399

Klinger BA, Marotzke J (2000) Meridional heat transport by the subtropical cell. J Phys Oceanogr 30:696-705

Lorenz SJ, Lohmann G (2004) Acceleration technique for Milankovitch type forcing in a coupled atmosphere-ocean circulation model: method and application for the Holocene. Clim Dyn 23:727-743

Lucas MA, Hirschi JJ, Stark JD, Marotzke J (2005) The response of an idealized ocean basin to variable buoyancy forcing. J Phys Oceanogr 35:601-615

Manabe S, Stouffer RJ (1988) Two stable equilibria of a coupled ocean-atmosphere model. J Clim 1(9):841-866

Marotzke J, Klinger BA (2000) The dynamics of equatorially asymmetric thermohaline circulations. J Phys Oceanogr 30:955-970

McManus JF, Francois R, Gherardi JM, Keigwin LD, Brown-Leger S (2004) Collapse and rapid resumption of Atlantic meridional circulation linked to deglacial climate changes. Nature 428:834837

Milankovitch M (1920) Theorie Mathématique des Phénomènes Thermiques produits par la Radiation Solaire. Gauthier-Villars, Paris

Min S-K, Legutke S, Hense A, Kwon W-T (2005) Internal variability in a 1000-yr control simulation with the coupled climate model ECHO-G-II. El Nino Southern Oscillation and North Atlantic Oscillation. Tellus 57A:622-640

Pickard GL, Emery WJ (1990) Descriptive physical oceanography. Pergamon, Oxford, $320 \mathrm{pp}$

Rahmstorf S, Ganopolski A (1999) Long-term global warming scenarios computed with an efficient coupled climate model. Clim Change 43:353-367

Ruddiman WF (2001) Earth's climate: past and future. W.H. Freeman and company, New York, $465 \mathrm{pp}$

Turney CSM, Kershaw AP, Clemens SC, Branch N, Moss PT, Fifield LK (2004) Millennial and orbital variations of El Nino/Southern Oscillation and high-latitude climate in the last glacial period. Nature 428:306-310

Tziperman E, Stone L, Cane MA, Jarosh H (1994) El-Nino chaos: overlapping of resonances between the seasonal cycle and the Pacific ocean-atmosphere oscillator. Science 264(5155):72-74

Webb DJ (1995) Development of the OCCAM global model for the Cray T3D. WOCE report no 125/95, WOCE International Project Office, 24

Webb DJ (1996) An ocean model code for array processor computers. Comp Geosci 22:569-578

Wunsch C (2006) Abrupt climate change: an alternative view. Quat Res 65:191-203 